\title{
Effect of hemodialysis on blood ammonia level among cirrhotic patients undergoing hemodialysis
}

Atef Aboelfetouh Ibrahim, Ahmed Mohammed Alashkar, Ahmed Khairallah Nephrology Unit, Faculty of Medicine, Al-Azhar University, Cairo, Egypt

Corresponding author: Ahmed Abdo Khairallah, E-mail: ahmed.abdo.khairallah@gmail.com

\begin{abstract}
Background: Uremia results in a characteristic breath odor (uremic fetor) which is largely due to its high ammonia content. Earlier studies have shown a strong correlation between breath ammonia and blood urea levels and a 10-fold reduction in breath ammonia after hemodialysis in patients with chronic kidney disease. Potential sources of breath ammonia include: (i) local ammonia production from hydrolysis of urea in the oropharyngeal and respiratory tracts by bacterial flora, and (ii) release of circulating blood ammonia by the lungs. While the effects of uremia and hemodialysis on breath ammonia are well known while their effects on blood ammonia are unknown and were explored here.

Methods: Blood samples were obtained from 56 hemodialysis patients (immediately before and after dialysis). Blood levels of ammonia, creatinine, arterial blood gases, and electrolytes were measured.

Results: There was significant fall in serum creatinine following hemodialysis with significant increase in blood ammonia. Moreover, cirrhotic patients with highbicarbonate showed a significant more increase in ammonia and significant increase in incidence of hyper-ammonemia to that of non-cirrhotic and low-bicarbonate. Furthermore, the increase in serum bicarbonate showed a significant correlation to the change of blood ammonia following dialysis.

Conclusion: The fall in blood creatinine concentration following hemodialysis is paradoxically accompanied by a rise in blood ammonia in hemodialysis subjects, contrasting the reported effect on breath ammonia. The mechanism of the posthemodialysis rise in blood ammonia may be due alkalotic change in $\mathrm{PH}$. The observed rise in blood ammonia level was directly related to the rise in blood bicarbonate and with aggravation of alkalotic state in cirrhotic patients. The rise in blood bicarbonate is associated with increased incidence of hyper-ammonemia among cirrhotic patients.
\end{abstract}

Keywords: Uremia, chronic kidney disease, urea, inflammation, dialysis INTRODUCTION

Prior to the advent of modern laboratory techniques, characterization of the smell of patients breath was a common tool used by ancient clinicians for the diagnosis of various diseases. A prime example of a disease with a characteristic breath odor is renal failure. The fishy smell of these patients' breath, which is commonly described as uremic fetor primarily due to the presence of large amounts of ammonia in their exhaled air ${ }^{(1)}$. In an earlier study Narasimhan et al. ${ }^{(2)}$ found marked elevation of ammonia (NH3) concentration in the breath of a group of end-stage renal disease (ESRD) patients. Breath ammonia level in the study population is directly correlated with their blood urea concentration. The fall in urea concentration was accompanied by a 10fold drop in breath ammonia level, from 1500 to $2000 \mathrm{ppb}$ before hemodialysis to 150-200 ppb after hemodialysis (2).

Ammonia in the body is derived from two sources: (i) Cleavage of the amino groups of amino acids followed by its conversion to urea by the liver and to ammonium (NH4) by the renal tubular epithelial cells (3, 4). Conversion of ammonia to ammonium $\left[\mathrm{NH}_{3}+\mathrm{H}^{+} \longrightarrow \mathrm{NH}_{4}{ }^{+}\right]$in the renal level have not been previously investigated. The present study was undertaken to address this issue.

\section{PATIENTS AND METHODS}

In this study, Patients were divided into 4 groups:

1- Group I: indicated ESRD, non-cirrhotic 
with low serum bicarbonate following dialysis $(\leq 22 \mathrm{mEq} / \mathrm{L} ; \mathrm{no}=14)$.

2- Group II: indicated ESRD, noncirrhotic with high serum bicarbonate following dialysis ( $>22 \mathrm{mEq} / \mathrm{L}$; no=12).

3- Group III: indicated ESRD, cirrhotic with low serum bicarbonate following dialysis $($ no $=12)$.

4- Group IV: indicated ESRD, cirrhotic with high serum bicarbonate following dialysis $($ no $=18)$.

All subjects had been subjected to:

1. Demographic data assessment: (age, sex, height and BMI).

2. History taking: Full history taking focusing on history of hepatic encephalopathy.

4. Thorough clinical examination:

General examination: focusing on assessment of the patient's general condition.

Local examination: focusing on signs of hepatic encephalopathy and ammonia toxicity.

5. ABG before and after hemodialysis.

6. Serum creatinine before and after hemodialysis.

7. Blood ammonia before and after hemodialysis.

8. Hemoglobin before and after hemodialysis.

9. Serum albumin before and after hemodialysis.
The study was approved by the Ethics Board of Al-Azhar University.

\section{Statistical analyses}

One-way and Two-way ANOVA, Tukey's post-test, unpaired t-test, Pearson's correlation tests were used in analysis of the data, which were expressed as mean \pm SD. Pvalues less than 0.05 were considered significant. The data were collected, revised, verified and analyzed statistically.

\section{Blood collection}

Blood samples were obtained from the vascular access in the hemodialysis patients immediately before and after a hemodialysis session. Blood ammonia level was measured by the Clinical Laboratory center at UCI Medical Center within 30 minutes of collection. Blood creatinine, urea, electrolytes, hemoglobin, and white blood cells count were measured on automated bioanalyzers at the UCI Medical Center, central laboratory.

\section{RESULTS}

There were no statistically significant differences between all groups as regards age, BMI, hypertension, diabetes, smoking, cause of hemodialysis, Child-Pugh score and past history of hepatic encephalopathy (Tables $1 \&$ 2).

Table (1): Comparison between the two groups as regards demographic parameters (using t-test).

\begin{tabular}{|l|l|l|l|l|l|}
\hline & Group & Mean & Std. Deviation & p-value & Significance \\
\hline $\begin{array}{l}\text { Age } \\
\text { (years) }\end{array}$ & Group 1 & 37.43 & 13.89 & 0.4608 & NS \\
\cline { 2 - 4 } & Group 2 & 40.54 & 17.38 & & \\
\hline $\begin{array}{l}\text { BMI } \\
\left(\mathbf{k g} / \mathbf{m}^{2}\right)\end{array}$ & Group 1 & 25.83 & 5.49 & 0.305 & NS \\
\cline { 2 - 4 } & Group 2 & 27.31 & 5.16 & & \\
\hline
\end{tabular}

Table (2): Comparison between the two groups as regard different present history data (using Chisquare test).

\begin{tabular}{|c|c|c|c|c|c|}
\hline & & \multicolumn{2}{|l|}{ group } & \multirow[t]{2}{*}{ p-value } & \multirow[t]{2}{*}{ Significance } \\
\hline & & Group 1 & Group 2 & & \\
\hline \multirow[t]{2}{*}{ Sex } & Male & 20 & 16 & \multirow{2}{*}{0.6896} & \multirow{2}{*}{ NS } \\
\hline & Female & 10 & 10 & & \\
\hline \multirow[t]{2}{*}{ HTN } & Yes & 22 & 20 & \multirow{2}{*}{0.1128} & \multirow{2}{*}{ NS } \\
\hline & No & 8 & 6 & & \\
\hline \multirow[t]{2}{*}{ DM } & Yes & 4 & 8 & \multirow[t]{2}{*}{0.757} & \multirow[t]{2}{*}{ NS } \\
\hline & No & 26 & 18 & & \\
\hline \multirow[t]{2}{*}{ Smoking } & Yes & 9 & 6 & \multirow[t]{2}{*}{0.5596} & \multirow[t]{2}{*}{ NS } \\
\hline & No & 21 & 20 & & \\
\hline
\end{tabular}

There was significant fall in serum creatinine following hemodialysis with significant increase in 
blood ammonia. Moreover, cirrhotic patients with high-bicarbonate showed a significant more increase in ammonia and significant increase in incidence of hyper-ammonemia to that of noncirrhotic and low-bicarbonate. Furthermore, the increase in serum bicarbonate showed a significant correlation to the change of blood ammonia following dialysis (Tables $3 \& 6$, Figures $1 \& 2$ ).

Table (3): Effect of dialysis on arterial blood ammonia among cirrhotic and non-cirrhotic patients

\begin{tabular}{|c|c|c|c|c|c|c|}
\hline & Group & \begin{tabular}{|l} 
non-cirrhotic \\
high-bicarbonate
\end{tabular} & $\begin{array}{l}\text { non-cirrhotic } \\
\text { low-bicarbonate }\end{array}$ & $\begin{array}{l}\text { Cirrhotic high- } \\
\text { bicarbonate }\end{array}$ & $\begin{array}{|ll|}\begin{array}{l}\text { Cirrhotic } \\
\text { bicarbonate }\end{array} & \text { low- } \\
\end{array}$ & p-value \\
\hline \multirow{3}{*}{$\begin{array}{l}\text { Ammonia } \\
(\mu \mathrm{mol} / \mathrm{L})\end{array}$} & Pre-HD & $26.03 \pm 0.34$ & $32.61 \pm 8$ & $26.49 \pm 2.86$ & $28.87 \pm 5.8$ & \multirow[t]{3}{*}{$<0.0001$} \\
\hline & Post-HD & $24.14 \pm 3.53 *$ & $27.85 \pm 5.023^{\mathrm{a}}$ & $17.97 \pm 7.02 *$ & $32.74 \pm 6.19^{\mathrm{c} *}$ & \\
\hline & $\Delta$ & $-1.89 \pm 3.19$ & $4.76 \pm 8.61^{\mathrm{a}}$ & $-8.52 \pm 6.1$ & $3.87 \pm 4.54^{\mathrm{c}}$ & \\
\hline
\end{tabular}

Data are presented as the mean \pm S.D ( $\mathrm{n}=18,12,10,14$ for group 1, 2, 3, 4 respectively). 2-way ANOVA followed by post-hoc test; ${ }^{a}$ Significant different to group-1 at post-dialysis $(\mathrm{p}<0.05),{ }^{b}$ Significant different to group-2 at post-dialysis ( $\mathrm{p}<0.05)$, ${ }^{\mathrm{c}}$ Significant different to group-3 at postdialysis $(\mathrm{p}<0.05), *$ Significant different to respective group at pre-dialysis $(\mathrm{p}<0.05)$.

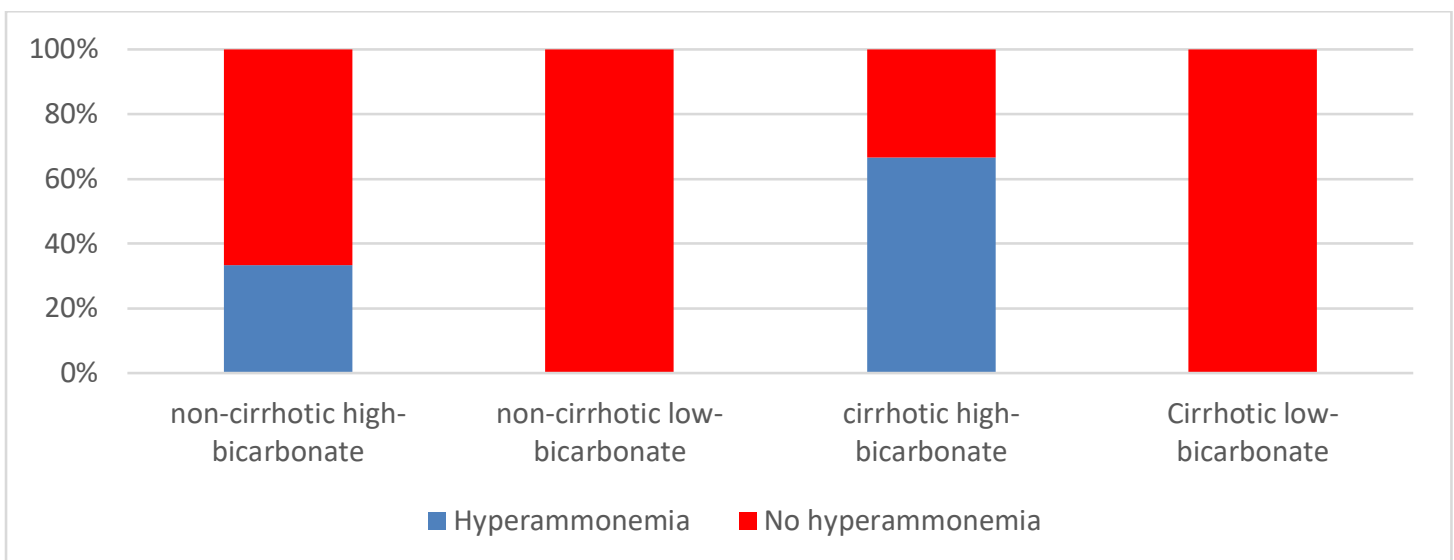

Figure (1): Effect of dialysis on incidence of hyperammonemia $(>32 \mu \mathrm{mol} / \mathrm{L})$ among cirrhotic and non-cirrhotic patients

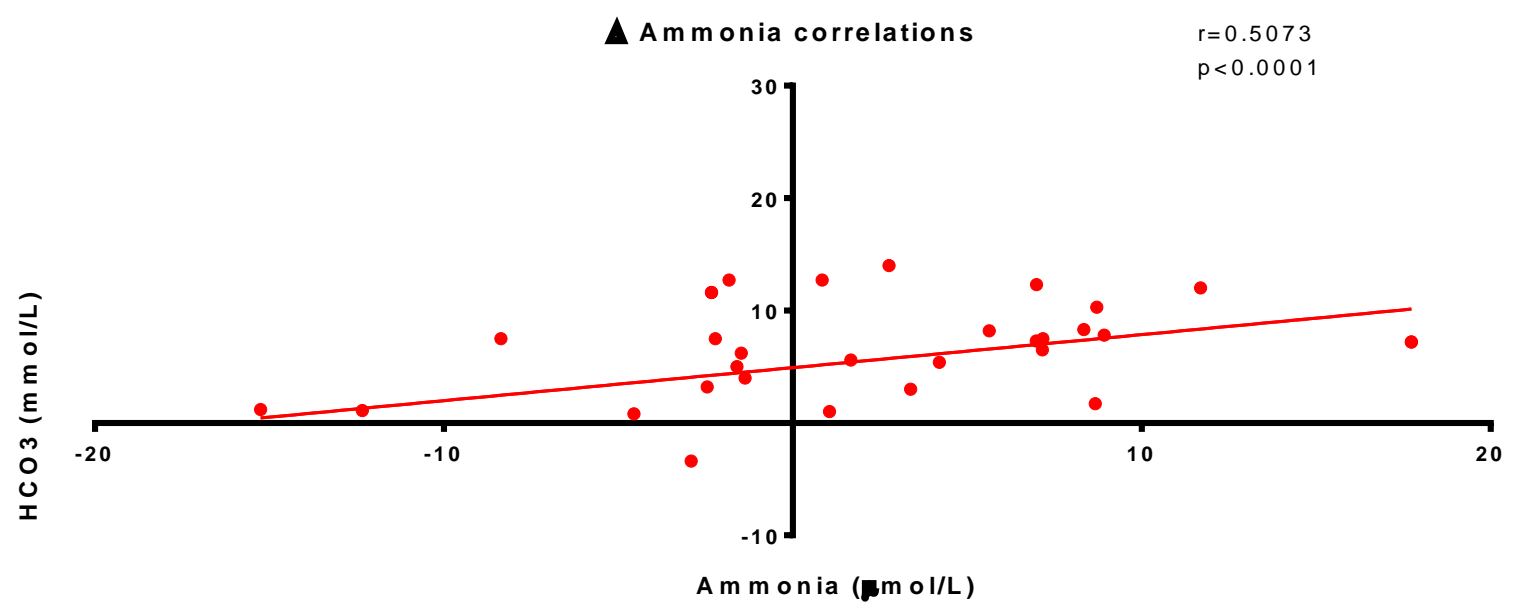

Figure (2): Correlation of blood ammonia and arterial bicarbonate among cirrhotic and non-cirrhotic patients (Pearson correlation test). Correlation coefficient ( $r$-value) considered weak if $\langle 5$, strong if $\rangle$ 5 (p-value <0.05).

Concerning arterial gases parameters, there were no statistically significant differences between all groups as regards $\mathrm{PO}_{2}$. However, cirrhotic patients showed significant decrease in $\mathrm{PCO}_{2}$ with significant increase in $\mathrm{PH}$ in cirrhotic patients due to compensated respiratory alkalosis (p-value $>0.05$ ). Moreover, there was no significant correlation with change in blood ammonia following hemodialysis. In addition, there was no significant difference regarding incidence of hyperammonemia among all groups. However, there was a significant increase in incidence of alkalosis in 
cirrhotic group with hypocapnia (Tables $4 \& 6$ ).

Table (4): Effect of dialysis on PH, bicarbonate and arterial blood gases among cirrhotic and noncirrhotic patients

\begin{tabular}{|c|c|c|c|c|c|c|}
\hline & Group & \begin{tabular}{|l} 
non-cirrhotic \\
low-biocarb
\end{tabular} & $\begin{array}{c}\text { non-cirrhotic } \\
\text { high-biocarb }\end{array}$ & \begin{tabular}{|l|}
$\begin{array}{l}\text { Cirrhotic } \\
\text { biocarb }\end{array}$ \\
\end{tabular} & \begin{tabular}{|l|}
$\begin{array}{l}\text { Cirrhotic high- } \\
\text { biocarb }\end{array}$ \\
\end{tabular} & p-value \\
\hline \multirow[t]{3}{*}{$\mathbf{P H}$} & Pre-HD & $7.29 \pm 0.06$ & $7.28 \pm 0.04$ & $7.28 \pm 0.05$ & $7.36 \pm 0.05$ & \multirow[t]{3}{*}{0.7183} \\
\hline & Post-HD & $7.39 \pm 0.07 *$ & $7.37 \pm 0.03^{*}$ & $7.36 \pm 0.09^{*}$ & $7.45 \pm 0.08^{\mathbf{b c} *}$ & \\
\hline & $\Delta$ & $0.1 \pm 0.07$ & $0.09 \pm 0.05$ & $0.07 \pm 0.07$ & $0.1 \pm 0.07$ & \\
\hline \multirow{3}{*}{$\begin{array}{l}\mathrm{HCO3} \\
(\mathrm{mmol} / \mathrm{L})\end{array}$} & Pre-HD & $17.21 \pm 0.46$ & $15.9 \pm 1.31$ & $21.07 \pm 2.9$ & $19.12 \pm 2.27$ & \multirow[t]{3}{*}{$<0.0001$} \\
\hline & Post-HD & $20.07 \pm 2 *$ & $23.87 \pm 1.26^{\mathbf{a} *}$ & $21.05 \pm 0.79 *$ & $26.86 \pm 3.11^{\mathbf{b c}}$ & \\
\hline & $\Delta$ & $2.86 \pm 2.47$ & $7.967 \pm 1.737^{\mathrm{a}}$ & $-0.017 \pm 2.609$ & $7.744 \pm 3.97^{\mathrm{c}}$ & \\
\hline \multirow{3}{*}{$\begin{array}{l}\text { pCO2 } \\
(\mathrm{mmHg})\end{array}$} & Pre-HD & $35.84 \pm 3.75$ & $35.73 \pm 1.83$ & $31.42 \pm 3.85$ & $30.9 \pm 4.75$ & \multirow[t]{3}{*}{0.0462} \\
\hline & Post-HD & $38.88 \pm 2.18$ & $39.11 \pm 3.39$ & $34.39 \pm 5.45$ & $33.5 \pm 8.18^{\mathbf{b}}$ & \\
\hline & $\Delta$ & $3.04 \pm 3.79$ & $3.38 \pm 2.94$ & $2.98 \pm 4.38$ & $2.6 \pm 6.98$ & \\
\hline \multirow{3}{*}{$\begin{array}{l}\text { pO2 } \\
(\mathrm{mmHg})\end{array}$} & Pre-HD & $103.2 \pm 21.85$ & $98.65 \pm 10.21$ & $58.88 \pm 35.49$ & $94.7 \pm 32.43$ & \multirow[t]{3}{*}{0.3394} \\
\hline & Post-HD & $102.84 \pm 18.75$ & $119.72 \pm 29.38$ & $70.48 \pm 31.97$ & $98.96 \pm 22.69^{c}$ & \\
\hline & $\Delta$ & $-0.36 \pm 21.23$ & $21.07 \pm 27.1$ & $11.6 \pm 44.67$ & $4.26 \pm 30.69$ & \\
\hline
\end{tabular}

Data are presented as the mean \pm S.D ( $\mathrm{n}=18,12,10,14$ for group $1,2,3,4$ respectively). 2-way ANOVA followed by post-hoc test; ${ }^{a}$ Significant different to group-1 at post-dialysis ( $\left.p<0.05\right),{ }^{b}$ Significant different to group-2 at post-dialysis ( $\mathrm{p}<0.05$ ), ${ }^{\mathrm{c}}$ Significant different to group-3 at postdialysis $(\mathrm{p}<0.05), *$ Significant different to respective group at pre-dialysis $(\mathrm{p}<0.05)$.

Concerning renal parameters, there were no statistically significant differences between all groups as regards hemoglobin, albumin, creatinine, $\mathrm{Na}$ and $\mathrm{K}$ ( $\mathrm{p}$-value $>0.05$ ). Moreover, there was no significant correlation with change in blood ammonia flowing hemodialysis. In addition, there was no significant difference regarding incidence of hyper-ammonemia among all groups (Table 5, 6).

Table (5): Effect of dialysis on hemoglobin and different serum biochemistry among cirrhotic and non-cirrhotic patients

\begin{tabular}{|c|c|c|c|c|c|c|}
\hline & Group & $\begin{array}{l}\text { non-cirrhotic } \\
\text { low-biocarb }\end{array}$ & $\begin{array}{c}\text { non-cirrhotic } \\
\text { high-biocarb }\end{array}$ & $\begin{array}{l}\text { Cirrhotic low- } \\
\text { biocarb }\end{array}$ & \begin{tabular}{|l|} 
Cirrhotic \\
high-biocarb
\end{tabular} & p-value \\
\hline \multirow{3}{*}{$\begin{array}{l}\text { Hemoglobin } \\
\text { (g/dL) }\end{array}$} & Pre-HD & $10.94 \pm 1.84$ & $9.7 \pm 2.86$ & $8.8 \pm 2.09$ & $8.828 \pm 2.43$ & \multirow[t]{3}{*}{0.9245} \\
\hline & Post-HD & $10.9 \pm 1.82$ & $9.68 \pm 2.673$ & $8.817 \pm 2.202$ & $8.83 \pm 2.17$ & \\
\hline & $\Delta$ & $-0.043 \pm 0.165$ & $-0.017 \pm 0.229$ & $0.017 \pm 0.22$ & $0.006 \pm 0.31$ & \\
\hline \multirow{3}{*}{$\begin{array}{l}\text { Albumin } \\
(\mathrm{g} / \mathrm{dL})\end{array}$} & Pre-HD & $3.89 \pm 0.3$ & $4.067 \pm 0.45$ & $3.817 \pm 0.54$ & $3.9 \pm 0.32$ & \multirow{3}{*}{0.584} \\
\hline & Post-HD & $3.86 \pm 0.28$ & $4.02 \pm 0.42$ & $3.75 \pm 0.49$ & $3.88 \pm 0.3$ & \\
\hline & $\Delta$ & $-0.029 \pm 0.13$ & $-0.05 \pm 0.05$ & $-0.067 \pm 0.078$ & $-0.022 \pm 0.088$ & \\
\hline \multirow{3}{*}{$\begin{array}{l}\text { Creatinine } \\
(\mathrm{mg} / \mathrm{dL})\end{array}$} & Pre-HD & $7.88 \pm 3.76$ & $11.89 \pm 1.28$ & $8.845 \pm 2.05$ & $9.65 \pm 2.43$ & \multirow{3}{*}{0.0094} \\
\hline & Post-HD & $5.59 \pm 2.93^{*}$ & $5.67 \pm 0.88^{\mathbf{a}}$ & $4.13 \pm 1.83^{*}$ & $3.16 \pm 1.27^{\mathbf{b} *}$ & \\
\hline & $\Delta$ & $-2.29 \pm 6.09$ & $-6.22 \pm 1.19^{a}$ & $-4.71 \pm 2.34$ & $-6.49 \pm 2.45$ & \\
\hline \multirow{3}{*}{$\begin{array}{l}\mathrm{Na} \\
(\mathrm{mmol} / \mathrm{L})\end{array}$} & Pre-HD & $129.67 \pm 1.048$ & $133 \pm 3.4$ & $125.45 \pm 4.03$ & $128.24 \pm 5.54$ & \multirow{3}{*}{0.3469} \\
\hline & Post-HD & $134.93 \pm 4.69$ & $135.63 \pm 3.62 *$ & $127.18 \pm 4.37$ & $130.11 \pm 3.67^{\mathbf{b}}$ & \\
\hline & $\Delta$ & $5.26 \pm 5.43$ & $2.63 \pm 5.76$ & $1.73 \pm 5.08$ & $1.87 \pm 6.51$ & \\
\hline \multirow{3}{*}{$\begin{array}{l}\mathbf{K} \\
(\mathbf{m m o l} / \mathrm{L})\end{array}$} & Pre-HD & $4.71 \pm 0.68$ & $4.6 \pm 0.65$ & $4.34 \pm 0.29$ & $4.88 \pm 1.13$ & \multirow{3}{*}{0.3689} \\
\hline & Post-HD & $3.6 \pm 0.43^{*}$ & $3.28 \pm 0.29 *$ & $3.34 \pm 0.35^{*}$ & $3.43 \pm 0.86^{*}$ & \\
\hline & $\Delta$ & $-1.11 \pm 0.45$ & $-1.32 \pm 0.47$ & $-1 \pm 0.61$ & $-1.46 \pm 1.1$ & \\
\hline
\end{tabular}

Data are presented as the mean \pm S.D $(\mathrm{n}=18,12,10,14$ for group $1,2,3,4$ respectively). 2-way 
ANOVA followed by post-hoc test; ${ }^{a}$ Significant different to group-1 at post-dialysis $(\mathrm{p}<0.05),{ }^{\text {b }}$ Significant different to group-2 at post-dialysis ( $\mathrm{p}<0.05$ ), ${ }^{\mathrm{c}}$ Significant different to group-3 at postdialysis $(\mathrm{p}<0.05), *$ Significant different to respective group at pre-dialysis $(\mathrm{p}<0.05)$.

Table (6): Effect of different serum and blood components on level of blood ammonia among cirrhotic and non-cirrhotic patients

\begin{tabular}{|l|l|l|l|}
\hline & Correlation coefficient & P-value & Significant \\
\hline$\Delta$ ammonia vs. $\Delta$ HCO3 & 0.5073 & $<0.0001$ & Yes \\
\hline$\Delta$ ammonia vs. $\Delta$ PH & 0.05301 & 0.6980 & No \\
\hline$\Delta$ ammonia vs. $\Delta$ pCO2 2 & 0.07769 & 0.5693 & No \\
\hline$\Delta$ ammonia vs. $\Delta$ pO2 & -0.09345 & 0.4933 & No \\
\hline$\Delta$ ammonia vs. $\Delta$ Na & -0.185 & 0.1722 & No \\
\hline$\Delta$ ammonia vs. $\Delta$ K & 0.04976 & 0.7157 & No \\
\hline$\Delta$ ammonia vs. $\Delta$ Creatinine & -0.1783 & 0.1885 & No \\
\hline$\Delta$ ammonia vs. $\Delta$ Albumin & 0.06374 & 0.6407 & No \\
\hline$\Delta$ ammonia vs. $\Delta$ HB & -0.1443 & 0.2886 & No \\
\hline Coma & cofficle &
\end{tabular}

Correlation coefficient ( $r$-value) considered weak if $<5$, strong if $>5$ (p-value $<0.05$ ).

\section{DISCUSSION}

Although there have been some limited studies of the effect of regular hemodialysis on blood ammonia, this study prospectively investigated role of regular HD on blood ammonia and incidence of hyperammonemia. This prospective study also detailed the difference between cirrhotic and non-cirrhotic patients on RHD regarding change in ammonia, bicarbonate, $\mathrm{PH}$, biochemical substances and electrolytes. Furthermore, it was to investigate the impact of different intra-dialysis variables including change in bicarbonate, $\mathrm{PH}$, biochemical substances and electrolytes on change of blood ammonia.

The statistical differences regarding patient characteristics (age, sex, BMI, DM, HTN, smoking, cause of HD, cause of cirrhosis, child-pugh and history of HE) among the different groups are insignificant. This comes in agreement with Rettig et al. ${ }^{(5)}$ and Schena et al. ${ }^{(6)}$.

Retention of urea in renal failure leads to the rise in its concentration in the body fluids and its heavy influx into the gastrointestinal tract, which is accompanied by marked alteration of the gut microbial flora and dominance of urease-possessing bacteria ${ }^{(7-9)}$. Hydrolysis of urea by microbial urease leads to formation of large quantities of ammonia [NH2-CO-NH2 + $\mathrm{H} 2 \mathrm{O}$

$\mathrm{CO} 2+2 \mathrm{NH} 3]$. Most of the ammonia generated in the gut is converted to ammonium hydroxide $[\mathrm{NH} 3+\mathrm{H} 2 \mathrm{O}$
$\mathrm{NH} 4 \mathrm{OH}]$, which accounts for the elevated $\mathrm{pH}$ of the intestinal milieu in patients with renal failure $(10,11)$. There is growing evidence indicating the role of intestinal barrier dysfunction and increased intestinal permeability (12-15). Some studies demonstrated massive losses of claudin-1, occludin, and zonula occludens-1 (the key protein constituents of the epithelial tight junction) in the colon, stomach, jejunum, and ileum of rats with CKD ${ }^{(14,16)}$. Other subsequent studies identified the role of urea-derived ammonium hydroxide in the disruption of the intestinal epithelial barrier structure $^{(16-19)}$. These observations confirm the local production of ammonia from hydrolysis of urea by the microbial flora in the oral, and pharyngeal cavities of uremic patients as the primary cause of their elevated breath ammonia level.

In contrast with elevated breath ammonia, our study revealed that after hemodialysis, ammonia showed a significant increase to that of pre-dialysis. This study doesn't go in line with Narasimhan et al. ${ }^{(2)}$ who previously reported that the fall in blood urea level following hemodialysis procedure correlates with a 10 -fold drop in breath ammonia level in ESRD patients. This study goes in line with Vaziri et al. ${ }^{(20)}$ who observed significantly raised blood ammonia levels in almost half of the subjects.

Moreover, there was a significant 
increase in $\mathrm{PH}$ and $\mathrm{HCO}_{3}^{-}$after hemodialysis and there was a significant more increase in cirrhotic patients with highbicarbonate to that of low-bicarbonate. Furthermore, only the increase in $\mathrm{HCO}_{3}{ }^{-}$ revealed a significant correlation with the magnitude of rise in blood ammonia level following hemodialysis. Interestingly, there was also a significant increase in incidence of hyper-ammonemia in high-bicarbonate cirrhotic patients to that of non-cirrhotic and low-bicarbonate groups. These observations may explain the rise of blood ammonia after hemodialysis, due to the acute change in acid-base status from mild acidosis in which the ammonia is held as nonvolatile ammonium $\left(\mathrm{NH}^{+}{ }_{4}\right)$ to the normal or alkalotic states where it exists partly in a volatile state $\left(\mathrm{NH}_{3}\right)$.

A second possible mechanism proposed by Vaziri et al. ${ }^{(20)}$ may explain rise of blood ammonia after HD, is the potential contribution of acute reduction of hepatic perfusion in the setting of ultrafiltration and decreased arterial pressures during hemodialysis. This transient liver ischemia may limit its ability to convert gut-derived ammonia to urea, thus raising systemic ammonia concentrations. Moreover, Vaziri et $\boldsymbol{a l} .{ }^{(20)}$ found a direct correlation between the extents of the fall in MAP with the rise in post-hemodialysis blood ammonia levels in a subset of patients.

Concerning arterial gases parameters, $\mathrm{PCO}_{2}$ and $\mathrm{PO}_{2}$ showed insignificant change during dialysis with insignificant correlation to change in blood ammonia. However, cirrhotic patients showed significant decrease in $\mathrm{PCO}_{2}$ with significant increase in $\mathrm{PH}$ in cirrhotic patients to that of noncirrhotic with high-bicarbonate. However, there was a significant increase in incidence of alkalosis in cirrhotic group with highbicarbonate and hypocapnia to that of noncirrhotic and low-bicarbonate. It is wellknown that patients with cirrhosis have an acid-base imbalance most commonly hyperventilatory alkalosis with decreased arterial carbon dioxide tension ${ }^{(21-24)}$. This hypocapnic alkalosis is metabolically compensated especially in class A cirrhosis (25). A balance between hypoalbuminemic alkalosis on the one hand and dilutional, diuretic-induced and unidentified ion acidosis on the other yields a net metabolic (complete or partial) compensation of the respiratory alkalosis in all classes ${ }^{(26)}$. The cirrhotic patient has normal or almost normal $\mathrm{pH}$, but this is the sum of a delicate equilibrium of several acid-base disturbances, which may be easily disturbed. Thereby, unbalanced in patients with infections, subacute bacterial peritonitis, or hemorrhage, where the cirrhotic patients may be at risk of developing metabolic acidosis or alkalosis earlier and more easily than patients without liver disease ${ }^{(27)}$.

Moreover, in this study, there was an insignificant decrease in $\mathrm{PCO}_{2}$ in all groups following the dialysis. This coincided with significant increase in $\mathrm{pH}$ post-dialysis and this might be due to correction of metabolic acidosis with subsequent diminished respiratory compensation by hypocapnia.

Concerning renal parameters, there was a significant decrease in creatinine and increase in potassium following the dialysis. However, there was no significant difference in albumin, hemoglobin, and sodium during the dialysis. Moreover, there was no significant difference between different groups (cirrhotic vs non-cirrhotic, highbicarbonate vs low-bicarbonate). Furthermore, there was no correlation between change in ammonia and change in these parameters. These result doesn't go in line with Narasimhan et al. (2) who previously reported that the fall in blood creatinine level following hemodialysis procedure correlates with a drop in breath ammonia level in ESRD patients.

An inverse relation is known to link blood potassium with renal synthesis and the release of ammonia (28). According to Zavagli et al. ${ }^{(29)}$ and Conn ${ }^{(30)}$ who reported that, in cirrhotic patients-stage I HE with high-normal potassium level, the survival and incidence of hepatic encephalopathy was improved than with low-normal potassium level. They referred this improvement to the induced decrease in blood $\mathrm{pH}$ with consequent depression of renal ammonia genesis and rise in the arterial and urine $\mathrm{NH}_{4}^{+} / \mathrm{NH}_{3}$ ratios. These factors reduce the entry of ammonia into the cells and enhance the urinary excretion of this metabolite, respectively. However, in our study, patients with ESRD had a severely inhibited renal ammonia genesis and therefore hyperkalemia will not 
influence the level of arterial ammonia.

\section{Conclusion}

Our study revealed that the fall in blood creatinine concentration following hemodialysis was paradoxically accompanied by a rise in blood ammonia in hemodialysis subjects, contrasting the reported effect on breath ammonia. The mechanism of the post-hemodialysis rise in blood ammonia might be due alkalotic change in $\mathrm{pH}$. The observed rise in blood ammonia level was directly related to the rise in blood bicarbonate and with aggravation of alkalotic state in cirrhotic patients. The rise in blood bicarbonate was associated with increased incidence of hyper-ammonemia among cirrhotic patients.

\section{REFERENCES}

1. Jankowski J, Westhof T, Vaziri ND, Ingrosso D, Perna AF (2014): Gases as uremic toxins: is there something in the air? Seminars in nephrology, 34(2):135-50.

2. Narasimhan LR, Goodman W, Patel CK (2001): Correlation of breath ammonia with blood urea nitrogen and creatinine during hemodialysis. Proc Natl Acad Sci U S A, 98(8):4617-21.

3. Weiner ID, Verlander JW (2013): Renal ammonia metabolism and transport. Comprehensive Physiology, 3(1):201-20.

4. Bergen WG, Wu G (2009): Intestinal nitrogen recycling and utilization in health and disease. The Journal of nutrition, 139(5):8215.

5. Rettig RA, Levinsky NG (1991) The ESRD Patient Population: Special Groups. In: Program CSMESRD, editor.Kidney Failure and the Federal Government. 91, National Academies: National Academies Press.

6. Schena FP (2000): Epidemiology of endstage renal disease: International comparisons of renal replacement therapy. Kidney international, 57:S39-S45.

7. Lee YT (1971): Urea concentration in intestinal fluids in normal and uremic dogs. Journal of surgical oncology, 3(2):163-8.

8. Vaziri ND, Wong J, Pahl M, Piceno YM, Yuan J, DeSantis TZ, et al. (2013): Chronic kidney disease alters intestinal microbial flora. Kidney international, 83(2):308-15.

9. Wong J, Piceno YM, DeSantis TZ, Pahl M, Andersen GL, Vaziri ND (2014):
Expansion of urease- and uricase-containing, indole- and p-cresol-forming and contraction of short-chain fatty acid-producing intestinal microbiota in ESRD. American journal of nephrology, 39(3):230-7.

10. Bourke E, Milne MD, Stokes GS (1966): Caecal $\mathrm{pH}$ and ammonia in experimental uraemia. Gut, 7(5):558-61.

11. Swales JD, Tange JD, Evans DJ (1972): Intestinal ammonia in uraemia: the effect of a urease inhibitor, acetohydroxamic acid. Clinical science, 42(1):105-12.

12. Stenvinkel $\mathbf{P}$ (2006): Inflammation in endstage renal disease: the hidden enemy. Nephrology (Carlton, Vic), 11(1):36-41.

13. Cachofeiro V, Goicochea $M$, de Vinuesa SG, Oubina P, Lahera V, Luno J (2008): Oxidative stress and inflammation, a link between chronic kidney disease and cardiovascular disease. Kidney international Supplement, 111:S4-9.

14. Vaziri ND, Yuan J, Rahimi A, Ni Z, Said H, Subramanian VS (2012): Disintegration of colonic epithelial tight junction in uremia: a likely cause of CKD-associated inflammation. Nephrology, dialysis, transplantation : official publication of the European Dialysis and Transplant Association - European Renal Association, 27(7):2686-93.

15. Ruiz S, Pergola PE, Zager RA, Vaziri ND (2013): Targeting the transcription factor Nrf2 to ameliorate oxidative stress and inflammation in chronic kidney disease. Kidney international, 83(6):1029-41.

16. Vaziri ND, Yuan J, Nazertehrani S, Ni Z, Liu S (2013): Chronic kidney disease causes disruption of gastric and small intestinal epithelial tight junction. American journal of nephrology, 38(2):99-103.

17. Vaziri ND, Yuan J, Norris K (2013): Role of urea in intestinal barrier dysfunction and disruption of epithelial tight junction in CKD. American journal of nephrology, 37(1):1-6.

18. Vaziri ND, Zhao YY, Pahl MV (2016): Altered intestinal microbial flora and impaired epithelial barrier structure and function in CKD: the nature, mechanisms, consequences and potential treatment. Nephrology, dialysis, transplantation : official publication of the European Dialysis and Transplant Association - European Renal Association, 31(5):737-46.

19. Lau WL, Kalantar-Zadeh K, Vaziri ND (2015): The gut as a source of inflammation in chronic kidney disease. Nephron, 130:92-8. 
20. Vaziri ND, Khazaeli M, Nunes ACF, Harley KT, Said H, Alipour O, et al. (2017): Effects of end-stage renal disease and dialysis modalities on blood ammonia level. Hemodialysis international International Symposium on Home Hemodialysis, 21(3):343-7.

21. Prytz H, Thomsen AC (1976): Acid-base status in liver cirrhosis. Disturbances in stable, terminal and portal-caval shunted patients. Scandinavian journal of gastroenterology, 11(3):249-56.

22. Oster JR, Perez GO (1986): Acid-base disturbances in liver disease. Journal of hepatology, 2(2):299-306.

23. Bendtsen F, Henriksen JH, Widding A, Winkler K (1987): Hepatic venous oxygen content in alcoholic cirrhosis and non-cirrhotic alcoholic liver disease. Liver, 7(3):176-81.

24. Moreau R, Hadengue A, Soupison T, Mamzer MF, Kirstetter P, Saraux JL, et al. (1993): Arterial and mixed venous acid-base status in patients with cirrhosis. Influence of liver failure. Liver, 13(1):20-4.

25. Funk GC, Doberer D, Osterreicher C, Peck-Radosavljevic M, Schmid M, Schneeweiss B (2005): Equilibrium of acidifying and alkalinizing metabolic acid- base disorders in cirrhosis. Liver international : official journal of the International Association for the Study of the Liver, 25(3):505-12.

26. Moller S, Hillingso J, Christensen E, Henriksen J (1998): Arterial hypoxaemia in cirrhosis: fact or fiction? Gut, 42(6):868-74.

27. Krag A, Moller S, Henriksen JH, Holstein-Rathlou NH, Larsen FS, Bendtsen F (2007): Terlipressin improves renal function in patients with cirrhosis and ascites without hepatorenal syndrome. Hepatology, 46(6):1863-71.

28. Tannen RL (1977): Relationship of renal ammonia production and potassium homeostasis. Kidney international, 11(6):45365.

29. Zavagli G, Ricci G, Bader G, Mapelli G, Tomasi F, Maraschin B (1993): The importance of the highest normokalemia in the treatment of early hepatic encephalopathy. Mineral and electrolyte metabolism, 19(6):362-7.

30. Conn HO (1994): Effects of high-normal and low-normal serum potassium levels on hepatic encephalopathy: Facts, half-facts or artifacts? Hepatology, 20(6):1637-40. 